those unregistered with GPs and those in anomalous positions-such as asylum seekers-will remain and will require alternative initiatives. Are sticks necessary as well as carrots-as in The Netherlands which links residency permits with $\mathrm{TB}$ screening? The autonomy of the individual in decisions about their own healthcare is fundamental in the UK and many other countries. The rights of those who actually have infectious $\mathrm{TB}$ which is a risk to others are, though, already constrained in the UK both by Act of Parliament (Public Health Act 1984) and potentially by decisions of the Courts. An extension of these limitations to those who merely might have active TB or who might get it in future would be a very hot political issue. TB, though, is already a hot political issue, ${ }^{4}$ and a rational, informed and wide-ranging debate is overdue. The present system is not adequate, and the 'status quo' is no longer a sensible or scientific position, but merely x-raying all potential immigrants would be worse. Answers as to the utility, yield and cost of various screening strategies should be readily obtainable at little additional cost because of the heterogeneity of what actually is being done across England and Wales, in both primary and secondary care, and sometimes across the interface between the two.

\section{Competing interests None.}

Provenance and peer review Not commissioned; not externally peer reviewed.
Thorax 2010;65:663-665

doi:10.1136/thx.2009.132373

\section{REFERENCES}

1. WHO. Global tuberculosis control-epidemiology, strategy, financing. Geneva: World Health Organization, 2009. http://www.who.int/tb/ publications/global report/2009/en/.

2. Health Protection Agency. Tuberculosis in the UK. Annual report on tuberculosis surveillance and control in the UK 2008. London. Health Protection Agency Centre for Infections, 2008 Oct 30. ISBN: 978-0-901144-96-6. http://www.hpa.org.uk/web/ HPAwebFile/HPAweb_C/1225268885463 (accessed 30 Oct 2009).

3. Cain KP, Haley CA, Armstrong LR, et al. Tuberculosis among foreign-born persons in the United States. Achieving tuberculosis elimination. Am J Respir Crit Care Med 2007:175:75-9.

4. Slack J. Migrants with TB should be sent home, say Tories. Daily Mail 28 June 2007.

5. Coker R, Bell A, Pitman R, et al. Tuberculosis screening in migrants in selected European countries shows wide disparities. Eur Respir J 2006;27:801-7.

6. Comstock GW. Epidemiology of tuberculosis. In: Reichman LB, Herschfield ES, eds. Tuberculosis. A comprehensive international approach. Vol 144 New York: Marcel Dekker Inc., 2000:129-56.

7. Ormerod LP. Tuberculosis screening and prevention in new entrants 1983-88. Respir Med 1990;84:269-71.

8. Erkens C, Slump E, Kamphorst M, et al. Coverage and yield of entry and follow-up screening for tuberculosis among new immigrants. Eur Respir $J$ 2008;32:153-61.

9. Gatwick health control confidential annual report 2002-2005. Crawley Primary Care trust. 2005

10. Health Protection Agency. Port health and inspection review. Report from the project team. 2006 Mar. http://www.hpa.org.uk/porthealth/ port_health.pdf (accessed 6 0ct 2009)

11. Ormerod LP, Green RM, Gray SM. Are there still effects on Indian Subcontinent ethnic tuberculosis of return visits? A longitudinal survey 1978-97. J Infect 2001;43:132-4

12. Tocque K, Bellis MA, Beeching N, et al. A casecontrol study of lifestyle risk factors associated with tuberculosis in the city of Liverpool, Northwest England. Eur Respir J 2001;18:959-64.

13. National Collaborating Centre for Chronic Conditions and the Royal College of Physicians. Tuberculosis: clinical diagnosis and management of tuberculosis, and measures for its prevention and control. A clinical guideline for the NHS in England and Wales, 2006. ISBN 86016227 0. http://guidance. nice.org.uk/CG33/niceguidance/pdf/English (accessed 6 0ct 2009)

14. Davies PDO, Drobniewski FA. The use of gammainterferon blood tests for the detection of latent tuberculosis infection. Eur Respir J 2006;28:1-3.

15. Hopewell PC, Pai M, Maher D, et al. International standards for tuberculosis care. Lancet Infect Dis 2006:6:710-25

16. Challenor J, Ormerod LP. An assessment of the impact of $\mathrm{BCG}$ vaccination on tuberculosis incidence in South Asian adult immigrants. Commun Dis Public Health 2002;5:338-40.

17. Choudry IW, Ormerod LP. An economic evaluation of the use of interferon gamma release assays in the screening of contacts and new entrants for latent TB. Thorax 2007;62(Suppl 3);S49 ppA22.

18. Ormerod LP. Serial surveys of tuberculosis nurse and support staff in England and Wales in 1998 and 2001. Commun Dis Public Health 2002;5:336-7.

19. Griffiths C, Sturdy P, Bothamley G, et al. Educational outreach to promote screening for tuberculosis in primary care: a cluster randomised trial. Lancet 2007;368:1528-34.

20. Cain KP, Benoit SR, Winston CA, et al. Tuberculosis among foreign-born persons in the United States. JAMA 2008; 300:405-12.

21. Kumar D, Watson JM, Charlett A, et al. Tuberculosis in England and Wales in 1993: results of a national survey. Thorax 1997;52:1060-67.

22. Joint Tuberculosis Committee of the British Thoracic Society. Control and prevention of tuberculosis: recommendations 2000. Thorax 2000;55:887-901.

\title{
Live and let die: is neutrophil apoptosis defective in severe asthma?
}

\author{
Helen Parfrey, Neda Farahi, Linsey Porter, \\ Edwin R Chilvers
}

Respiratory Medicine Division, Department of Medicine, University of Cambridge School of Clinical Medicine, Addenbrooke's Hospital, CUHNHSFT and Papworth Hospital NHS Foundation Trust, Cambridge, UK

Correspondence to Professor Edwin Chilvers, Respiratory Medicine Division, Department of Medicine, University of Cambridge School of Clinical Medicine, Box 157, Level 5, Addenbrooke's Hospital, Hills Road,

Cambridge CB2 000, UK; erc24@cam.ac.uk
Patients with severe asthma make up a relatively small proportion of the total population of patients with asthma yet account for a disproportional amount of asthma-related morbidity and healthcare utilisation. ${ }^{1} 2$ These patients are usually highly symptomatic, difficult to treat and can be extremely refractory to current treatments. As a consequence, understanding the mechanisms underlying this particular form of asthma is of paramount importance.

Morphological examination of the asthmatic airway reveals epithelial desquamation, thickening of the reticular basement membrane, mucus gland hyperplasia, goblet cell differentiation, angiogenesis and smooth muscle hypertrophy. ${ }^{3}$ In addition to these structural changes, an inflammatory cell infiltrate is evident within the airways comprising eosinophils, mast cells, lymphocytes and neutrophils. While eosinophils are the most characteristic inflammatory cell type present in mild to moderate asthma, the neutrophil seems to take centre stage more often in patients with severe disease. In fact, the neutrophil is one of the earliest inflammatory cells recruited to the airways following allergen exposure and is particularly evident in bronchoalveolar lavage samples and bronchial and transbronchial biopsies from patients with 
corticosteroid-resistant asthma, occupational asthma and fatal asthma as well as those with acute exacerbations. ${ }^{4-6}$ Furthermore, measures of asthma severity such as forced expiratory volume in $1 \mathrm{~s}$ correlate directly with the number of neutrophils present in the sputum and bronchial wall. ${ }^{78}$ There is also evidence of neutrophil activation and impaired function in the asthmatic airway. ${ }^{9} 10$ Moreover, neutrophil elastase is recognised to be highly histotoxic and results in epithelial and eosinophil activation, increased vascular permeability and promotion of transforming growth factor $\beta$ release which is linked to airways remodelling.

Given the propensity of neutrophils to die quite readily by 'constitutive' (ie, inbuilt time-dependent) apoptosis when studied in vitro, ${ }^{11}$ one major puzzle in airways research has been to determine how and why neutrophils persist in such large numbers in the asthmatic airway. It is also uncertain why some patients with severe asthma have an inflammatory response dominated by neutrophils while others have an eosinophil-dominated pattern of disease. Explanations include genetic and epigenetic diversity, unrecognised environmental effects such as occult occupational exposures or viral infection, and inherited or acquired differences in responses to treatment, in particular sensitivity to glucocorticosteroids. Intriguingly, human biopsy studies support the concept that inhaled corticosteroids, while highly effective in reducing eosinophilic inflammation in the airways, may be associated (perhaps causally) with a rebound increase in the number of airway neutrophils. ${ }^{12}$

For neutrophils to accumulate within the lung, an orderly procession of cell/ endothelial interaction, transcellular or pericellular transmigration and some degree of enhanced survival or defective egress is required. Based on sputum analysis, the principal signal coordinating neutrophil influx in severe asthma appears to be the cysteine-X-cysteine (CXC) chemokine interleukin 8 (IL-8; cysteine-Xcysteine chemokine ligand, CXCL), ${ }^{13}$ with additional contributions from IL-17, ${ }^{14}$ leukotriene B4 (LTB4), anaphylatoxins, growth-related oncogene a (GRO-a, CXCL1) and epithelial activating peptide 78 (ENA-78, CXCL5). ${ }^{15}$

Neutrophils access the lung parenchyma via pulmonary capillaries, a process which is strongly influenced by exposure of these cells to systemic priming agents that influence the size, shape, deformability and hence pulmonary transit time of this cell. In contrast, granulocytes arriving in the airway wall exit via the bronchial circula- tion at a post-capillary level and migrate via a classic 'rolling-tethering' paradigm involving (1) P-selectin glycoprotein ligand1, E-selectin ligand-1 and L-selectin mediated rolling; (2) chemokine-mediated cell activation; and (3) $\beta_{2}$-integrin-dependent adhesion and diapedesis where granulocytes move into tissues. ${ }^{16}$ As noted, a significant proportion of neutrophils cross the endothelial barrier by endocytosis, an active RhoG-dependent engulfment process, prior to negotiating the pericyte sheath and passing through "pre-perforated' regions of the basement membrane. ${ }^{17}$ The migration of neutrophils into the airway wall may facilitate the subsequent ingress of eosinophils. ${ }^{18}$

Once recruited into the airway, the neutrophil is left with a limited number of options which include transepithelial migration into the airway lumen, a process which some authors have suggested may represent a regulated and active disposal route for airway granulocytes ${ }^{19}$; migration back into the circulation (either directly or indirectly via lymphatics); transdifferentiation into macrophage cells ${ }^{20}$; cell death; or sustained residence. Neutrophil apoptosis (in contrast to necrosis) results in recognition and engulfment by macrophages, which is rapid and in itself promotes the resolution of inflammation and the restoration of normal tissue architecture. $^{21}$ The removal of neutrophils in this way serves to prevent the release of cytotoxic contents and thus protect host tissues. The precise timing and magnitude of neutrophil apoptosis in the asthmatic airway has been difficult to determine in vivo but offers a plausible exit strategy for these cells and one that has been observed in a number of other conditions characterised by airway neutrophilia. Consequently, factors that prolong the neutrophil lifespan by blocking apoptosis or impairing the clearance of apoptotic cells may be detrimental to this process and contribute towards the intense neutrophilic inflammation observed. Indeed, in the case of the eosinophil, it has been extremely difficult to identify any evidence of apoptosis within the microenvironment of the airway wall, despite the fact that these cells undergo apoptosis readily once they escape into the airway lumen. ${ }^{22}$

Unsurprisingly, neutrophil apoptosis turns out to be a highly regulated process. Recognised 'survival factors' include lipopolysaccharide, granulocyte-macrophage colony-stimulating factor, type I and II interferons, survivin and, rather surprisingly, hypoxia and glucocorticosteroids. ${ }^{23-26}$ With regard to the signalling pathways implicated in neutrophil survival, the PI3-kinase/AKT, NF- $\kappa B$, HIF-1 $\alpha$ and Mcl-1 pathways all seem to play substantial and contextspecific roles (see Cowburn et $a l^{15}$ ). Any or all of these mediators may contribute to an 'apoptosis-resistant' granulocyte phenotype which, if operational in the airway wall of patients with asthma, might severely impede neutrophil clearance.

The presence of eosinophil- or neutrophil-specific survival factors within the airways of such patients has been much debated but little explored. In this issue of Thorax, Uddin and colleagues confirm, using induced sputum, that a proportion of patients with severe atopic asthma have predominantly neutrophilic rather than eosinophilic inflammation (see page 684). ${ }^{27}$ Moreover, far fewer apoptotic neutrophils were evident in the former group, inferring a survival advantage for neutrophils in this cohort of patients. They were also able to show that the sputum sol phase recovered from the neutrophil-dominated patient group delayed apoptosis of naive blood-derived neutrophils. Unfortunately, experiments using a series of blocking antibodies and a panel of 'best guess' pharmacological inhibitors were unable to characterise the survival factor(s) further. Such clinical studies are challenging at the best of times, and the group deserves considerable credit for generating this data set. There are inevitable caveats including the intersubject variability in the number of apoptotic airway neutrophils observed, the use of induced sputum which provides only an indirect readout of the cellular microenvironment within the airway, the lack of biopsy data to examine the tissue rather than luminal compartment, and the very low numbers of apoptotic cells present at any one time $(<4 \%$ in this study). Critically, this study-in common with other reports-offers no insight into the true kinetics of neutrophil and eosinophil trafficking, nor any quantification of neutrophil clearance. It is possible, for instance, that the elevated level of neutrophil apoptosis seen in the severe 'neutrophilic' group reflects a failure of apoptotic cell recognition and removal (efferocytosis) rather than a true defect in apoptosis onset, as has been reported in the context of cystic fibrosis. The study is important, however, as it lends support to the view that neutrophil apoptosis and/or clearance may be defective in patients with asthma and shows that survival factors exist in the airway lining fluid which are specifically enriched in the 
context of severe asthma. Identifying the neutrophil survival factor(s) present in this patient group is clearly an important next step and, if targetable, may form the basis of a new therapeutic approach for this difficult-to-treat patient group.

While this study provides further evidence that neutrophil apoptosis may be deregulated in severe asthma, a number of key questions remain. We need to understand the dynamics of cell migration into and out of the airway wall and determine the true residency times and the relative contribution of apoptosis and, indeed, other non-apoptotic death mechanisms such as autophagy, NETosis ${ }^{28}$ and cytolysis in granulocyte clearance. We also need to understand the signals that block apoptosis in the airway wall (yet seemingly not in the airway lumen) and to determine what drives the switch from eosinophil- to neutrophildominated inflammation. Drugs which target the removal rather than the arrival of granulocytes in tissues are now emerging, ${ }^{29}$ and such agents may offer an important adjunct to current asthma treatments.

Funding MRC, Wellcome Trust, Asthma UK, BBSRC, NIHR Cambridge Biomedical Research Centre.

\section{Competing interests None.}

Provenance and peer review Commissioned; not externally peer reviewed.

Thorax 2010:65:665-667.

doi:10.1136/thx.2009.134270

\section{REFERENCES}

1. Serra-Batlles J, Plaza V, Morejón E, et al. Costs of asthma according to the degree of severity. Eur Respir J 1998;12:1322-6.

2. Antonicelli L, Bucca C, Neri M, et al. Asthma severity and medical resource utilisation. Eur Respir J 2004; 23:723-9.

3. Bousquet J, Jeffery PK, Busse WW, et al. Asthma. From bronchoconstriction to airways inflammation and remodeling. Am J Respir Crit Care Med 2000;161:1720-45.
4. Wenzel SE, Szefler SJ, Leung DY, et al. Bronchoscopic evaluation of severe asthma. Persistent inflammation associated with high dose glucocorticoids. Am J Respir Crit Care Med 1997:156:737-43.

5. Macedo P, Hew M, Torrego A, et al. Inflammatory biomarkers in airways of patients with severe asthma compared with non- severe asthma. Clin Exp Allergy 2009;39:1668-76

6. Macdowell AL, Peters SP. Neutrophil in asthma. Curr Allergy Asthma Rep 2007;7:464-8.

7. Woodruff PG, Khashayar R, Lazarus SC, et al. Relationship between airway inflammation, hyperresponsiveness, and obstruction in asthma. J Allergy Clin Immunol 2001;108:753-8.

8. Shaw DE, Berry MA, Hargadon B, et al. Association between neutrophilic airway inflammation and airflow limitation in adults with asthma. Chest 2007:132:1871-5

9. Baines KJ, Simpson JL, Scott RJ, et al. Immune responses of airway neutrophils are impaired in asthma. Exp Lung Res 2009;35:554-69.

10. Baines KJ, Simpson JL, Bowden NA, et al. Differential gene expression and cytokine production from neutrophils in asthma phenotypes. Eur Respir $J$ 2009;35:522-31.

11. Savill JS, Wyllie AH, Henson JE, et al. Macrophage phagocytosis of aging neutrophils in inflammation. Programmed cell death in the neutrophil leads to its recognition by macrophages. J Clin Invest 1989;83:865-75.

12. Hauber HP, Gotfried M, Newman K, et al. Effect of HFA-flunisolide on peripheral lung inflammation in asthma. J Allergy Clin Immunol 2003; 112:58-63

13. Kikuchi S, Kikuchi I, Takaku Y, et al. Neutrophilic inflammation and CXC chemokines in patients with refractory asthma. Int Arch Allergy Immunol 2009;149(Suppl 1):87-93.

14. Wilson RH, Whitehead GS, Nakano $\mathrm{H}$, et al. Allergic sensitization through the airway primes Th17dependent neutrophilia and airway hyperresponsiveness. Am J Respir Crit Care Med 2009:180:720-30

15. Cowburn AS, Condliffe AM, Farahi N, et al. Advances in neutrophil biology: clinical implications. Chest 2008:134:606-12.

16. Ley K, Laudanna C, Cybulsky Ml, et al. Getting to the site of inflammation: the leukocyte adhesion cascade updated. Nat Rev Immunol 2007;7:678-89.

17. van Buul JD, Allingham MJ, Samson T, et al. RhoG regulates endothelial apical cup assembly downstream from ICAM1 engagement and is involved in leukocyte trans-endothelial migration. J Cell Biol 2007;178:1279-93.

18. Kikuchi I, Kikuchi S, Kobayashi T, et al. Eosinophil trans-basement membrane migration induced by interleukin-8 and neutrophils. Am J Respir Cell Mol Biol 2006; 34:760-5.

19. Uller L, Persson CG, Erjefält JS. Resolution of airway disease: removal of inflammatory cells through apoptosis, egression or both? Trends Pharmacol Sci 2006;27:461-6.

20. Araki H, Katayama N, Yamashita Y, et al. Reprogramming of human postmitotic neutrophils into macrophages by growth factors. Blood 2004; 103:2973-80.

21. Savill J, Dransfield I, Gregory C, et al. A blast from the past: clearance of apoptotic cells regulates immune responses. Nat Rev Immunol 2002;12:965-75.

22. Uller $\mathbf{L}$, Persson $\mathrm{CG}$, Källström $\mathrm{L}$, et al. Lung tissue eosinophils may be cleared through luminal entry rather than apoptosis: effects of steroid treatment. Am J Respir Crit Care Med 2001:164: 1948-56.

23. Ward C, Chilvers ER, Lawson MF, et al. NF-KB activation is a critical regulator of human granulocyte apoptosis in vitro. $J$ Biol Chem 1999;274:4309-18.

24. van Raam BJ, Drewniak A, Groenewold V, et al. Granulocyte colony-stimulating factor delays neutrophil apoptosis by inhibition of calpains upstream of caspase-3. Blood 2008;

112:2046-54

25. Cowburn AS, Cadwallader KA, Reed BJ, et al. Role of PI3-kinase-dependent Bad phosphorylation and altered transcription in cytokine-mediated neutrophil survival. Blood 2002;100:2607-16.

26. Altznauer F, Martinelli S, Yousefi S, et al. Inflammation-associated cell cycle-independent block of apoptosis by survivin in terminally differentiated neutrophils. J Exp Med 2004;199:1343-54.

27. Uddin M, Nong G, Ward J, et al. Pro-survival activity for airway neutrophils in severe asthma. Thorax 2010:65:684-89

28. Fuchs TA, Abed U, Goosmann C, et al. Novel cell death program leads to neutrophil extracellular traps. J Cell Biol 2007:176:231-41.

29. Loynes CA, Martin JS, Robertson A, et al. Pivotal advance: pharmacological manipulation of inflammation resolution during spontaneously resolving tissue neutrophilia in the zebrafish. J Leukoc Biol 2010;87:203-12.

\section{British Thoracic Society Pleural Disease Guidelines - 2010 update}

\section{Nick Maskell, on behalf of the British Thoracic Society Pleural Disease Guideline Group}

Correspondence to Dr Nick Maskell, North Bristol Lung Centre, Southmead Hospital, Bristol, UK; nick.maskell@bristol.ac.uk

\section{INTRODUCTION}

Pleural disease remains common, affecting over 3000 people per million population each year. It therefore presents a significant contribution to the workload of respiratory physicians. These guidelines attempt to summarise the available evidence to aid the healthcare professional in delivering good quality patient care.

\section{AIMS AND OBJECTIVES OF THE GUIDELINE}

Since the last BTS pleural disease guidelines were published in $2003^{1}$ a large number of good quality primary research papers have been published and the guidelines need to reflect this new data. In addition, there was a need to develop new sections on local anaesthetic (LA) thoracoscopy and thoracic ultrasound to reflect changes in clinical practice. 